\title{
Research on Urban Renewal Path Under Actor Network
}

\author{
Zhoumin ${ }^{1, \mathrm{a}}$ \\ ${ }^{1}$ School of Public Administration and Politics and Law, Southwest Jiaotong University,Zhoumin, Chengdu, Sichuan, \\ China \\ a1127811786@qq.com
}

\begin{abstract}
Renewal is the eternal theme of a city and the source of its vitality. Urban development is a process of continuous renewal, and urban renewal is an important mechanism in urban self-regulation, Urban renewal is a complex and comprehensive construction activity, which includes many stakeholders. Different urban renewal modes and methods involve different participants. The traditional single-dominant mode of government can no longer achieve the goal of urban renewal. Only the mode of multi-subject participation can better implement urban renewal activities. Urban renewal is the main trend of future urban construction in China. At present, the vast majority of cities in China are in the post-urbanization development stage, and there are "urban diseases" such as dense population and scarce land resources. Therefore, it is very necessary to explore a perfect renewal mode and way. As a new epistemological perspective and theoretical analysis method for complex objects, the theory of actor network helps to clarify the interest demands and interaction relations of various actors in urban renewal.
\end{abstract}

Keywords: Urban renewal, Multiple subjects, Update mode, Urban development

\section{URBAN RENEWAL}

The concept of urban renewal originated in the West, It is a series of solutions proposed to deal with the problems in urban development. Urban renewal mainly refers to the necessary and planned reconstruction activities of the areas in the process of urban development that do not adapt to the social life of modern cities[1]. The earliest definition of urban renewal was the first research conference on urban renewal held in Holland in 1958. It was proposed that Urban renewal can be referred to as all the construction activities related to urban improvement, such as the repair and reconstruction of residential houses, the improvement of streets, parks and other environments, especially the improvement of land use patterns or regional areas, so as to create a comfortable living environment. [2]. Mr. Yang Jianqiang, a domestic scholar, put forward that "urban renewal is a long-term and comprehensive goal to improve the living environment, improve the quality of urban life, guarantee ecological safety, promote urban civilization and promote the harmonious development of society[3]. The purpose of urban renewal is to demolish, transform, invest and construct a declining area in the city, replace the declining physical space with a new urban function, and make it develop and prosper again. We will carry out urban renewal activities, pay more attention to the needs of the public, focus on addressing "urban diseases" in the process of urban development, improve the quality of cities, and build more comfortable and livable cities.

We will carry out urban renewal activities, pay more attention to the needs of the public, focus on addressing "urban diseases" in the process of urban development, improve the quality of cities, and build more comfortable and livable cities.

\section{ACTOR-NETWORK THEORY}

\subsection{Connotation And Main Content}

Actor-Network-Theory, Ant for short, It was first proposed by the Paris School of Sociology of Scientific Knowledge represented by French sociologists MichelCallon and BrunoLatour in the 1980s. Ant has developed a constructivist approach in which it argues that for a social system or network, there is essentially no difference between human and non-human abilities to act or participate[4]. The main core of Ant has three aspects: First, the actor. It can be a human being, or it can be an inhuman presence and power. "Actors" can be divided 
into core actors and other actors, and the core actor plays a leading role in network construction[5]. Second, the network. Human and non-human actors are linked to each other in equal identities, in chains and nets, in networks that extend to all corners. Third, translation. Translation is the process in which the core actors constantly translate the problems and interests of other actors into their own language, and it is the key to the construction of actor network. Translation usually has four stages[6]: Problem presentation, That is, let all actors accept the way to realize their respective interests, and put forward the key problem that must be solved to realize the interests of all parties; stakeholder is the core actors give corresponding interests to other actors according to their goals; recruitment is the core actor tries his best to bring other actors into the relevant network; mobilization is all the actors have a role to play in the network to be constructed[7].

Ant is a descriptive and explanatory method, which connects the actions and activities of actors and provides a good analytical framework for studying macro events from micro actions. The actors in ANT have equal status and form a network through relationship or connection, which provides a good analytical framework for exploring the path and mode of urban renewal.

\section{ANALYSIS FRAMEWORK OF ACTOR NETWORK FOR URBAN RENEWAL}

According to the actor network theory, the research on the actor network of urban renewal usually involves the following links: (1) Recognition of the actor subject; (2) Analysis of the process of actor translation, that is, how to make these actors participate in the network crowd through problem presentation, benefit grant, recruitment and mobilization; (3) How to balance the interests of actors? Actors of urban renewal are simply divided into two categories: human actors and nonhuman actors. Human actors can be divided into government departments, construction enterprises, scientific research institutions and the public, while nonhuman actors generally include infrastructure, policies, special events and environmental elements.

\section{THE TRANSLATION OF ACTOR NETWORK IN URBAN RENEWAL}

\subsection{Problems In The Process Of Urban Renewal}

Problem presentation is the first stage of the formation of the network alliance of urban renewal actors, It refers to that the core actors of the urban renewal network determine the status and interests of other relevant actors consistent with their own interest needs, and establish a mandatory point of passage (OPP) to make themselves an essential part of the network. The premise of problem-solving is to make clear who is the core actor in urban renewal. The system of our country determines the guiding role of the government. In urban renewal, local government has higher authority than other actors and is a natural core actor. To promote the benign development of urban renewal has the interests of improving urban development and governance so as to realize the sustainable development of the city, improve the social governance capacity of the government, and promote the modernization of government governance capacity and governance system. In order to achieve good governance, local governments must effectively integrate the will of the Party with the needs of the people for a better life, improve their own governance ability, translate other actors, and form a common actor. The task of local government as the core actor is :(1) Determine common goals; (2) Define the categories and interests of actors that may be included in the network, and balance the interests of each action; (3) Determine mandatory points of passage (OPP) that can be recognized and accepted by different actors.

From the perspective of the government, the traditional urban renewal has many problems, such as single transformation mode, weak planning management and insufficient support of the planning system[8]. Due to the accelerated process of urbanization, land resources are increasingly scarce and property rights are not clear. The existing land resources are no longer completely controlled by the government. Therefore, how to maximize the public interests has become an important issue for the government to solve in urban renewal. The central government formulated an overall urban renewal strategy and asked local governments to implement the strategy, However, due to local differences, the central government is often unable to adapt measures to local conditions and lacks a systematic implementation path of strategies, resulting in deviation or ineffectiveness of policy implementation, The key to the translation of the central government is to improve one's own ability development while completing the tasks of the superior. From the perspective of construction enterprises, developers and demolition units, as the operational core of the whole development and construction project, are the actual operators in the process of urban renewal and provide funds and engineering technologies for the construction. For developers, for the most to the economic benefits, there is an inevitable trend towards profitability. For demolition unit entrusted by the government or the developer's demolition for demolition of the old buildings, inevitably clashed with residents, is the relationship the most vulnerable part of the action network, how to coordinate the developers in the process of urban renewal and demolition in the interests of the units and residents is also the most important part of improve the network of actors. From the perspective of scientific research institutions, in the process of planning and design, it is necessary to collect the opinions of all 
parties to consider the design scheme, which is difficult to balance the interests of all parties comprehensively. From the perspective of the public, social organizations should take into account both social interests and residents' interests, and residents are often not active enough to participate.

The infrastructure of non-human actors in urban renewal is the natural system on which the city depends, and it is the guarantee for the city and its residents to obtain the natural ecological services continuously. All kinds of infrastructure is old, decrepit, disorderly layout, insufficient to meet the needs of residents. In urban renewal related policy, the government issued the relevant measures for the implementation of urban renewal notice, covers the content is very extensive, but the lack of implementation of to update city more perfect laws and regulations, the lack of a top-level leadership organization department, the primary responsibilities of the lack of a perfect update planning system, urban renewal are involved in the complex system of property rights, needs to be protected in policy and responsibility division.

In urban renewal of actors in the network, human actors and non-human actors have to solve problems, so as the key actors of the government will need to gather these questions of all the actors to "must" (OPP), a key point for the choice in and solve the problem of the actors, to obtain the required to achieve the biggest target.

\subsection{Benefit Endowment In The Urban Renewal Process}

Benefit grant is the second stage of the formation of actor network alliance, It aims to reinforce the defined roles of actors in the problem presentation process through the use of various devices and strategies, As a result, the actors are enlisted (the third link) to become members of the Urban Governance Network Alliance. In the actor network of urban renewal, benefit grant requires the government to change its role from the "paddler" to the "pilot", and the power is delegated to the market, society and the public. (1) Administrative recruitment: the government endusts the main responsible institutions with decision-making rights and supervision through improving the urban renewal institutions; (2) legal recruitment: the government through laws and regulations in the demolition, investment, compensation and other aspects of the behavior of the developers and demolition units of legal constraints; (3) Policy recruitment: through the promulgation of relevant urban renewal policies, the government clarifies the implementation of urban renewal subjects, implementation methods, implementation strategies, etc; (4) System recruitment: the government through the development of relevant systems for scientific research institutions and social organizations to improve human, material and financial resources; (5)Public service recruitment: The proximity of the government is low, so it is often difficult for other parties to get in touch with the government conveniently. Recruitment In The Process Of Urban Renewal. The participation of nonprofit organizations can enhance the efficiency and transparency of the network of urban renewal actors, and at the same time form a complete governance system of mutual supervision with government departments, enterprises, social organizations and residents. Community planners, volunteers and the like, to ensure the right of all members of society to participate actively in urban renewal.

\subsection{Conscription in the process of urban renewal}

Recruitment is the third stage of the formation of the network alliance of urban governance actors, It means that other actors in the urban renewal network accept (or align) the interests that are defined for them by the core actors of the network. Many elements of urban community renewal structure are not isolated and onesided, but connected and systematic. Diversified actors will participate in urban renewal in various ways with their own knowledge, resources and other elements. In order to realize their respective interests, cooperation becomes a realistic and effective option, Urban renewal is a complex and dynamic process, which needs to combine social interests with individual interests through coordination. By constructing a consultation, cooperation, integration, linkage and supervision mode, the government enlists actors from all sides to participate in the advice and advice of urban renewal planning.

\subsection{Mobilization In The Process Of Urban Renewal}

Mobilization is the fourth stage of the formation of the alliance of actors in urban renewal. Only when this stage is reached can a successful actor network be completed. Entrusted by the government, the Urban Renewal Bureau becomes the spokesperson of the whole actor network, exercises rights over other actors, builds a multi-coordination and communication platform, enables benign interactions among various subjects, builds a solid interest alliance of the actor network, and maintains the stable operation of the urban renewal network.

\section{EXPLORATION OF URBAN RENEWAL PATHS BASED ON ACTOR NETWORK}

The government plays the role of meta-governance, enlisting multiple actors to participate in the renewal network, Responsible for building a multi-party coordination and communication platform, and building a benign urban renewal path that includes governance, operation and security systems. 
First of all, the governance system should reflect the core role of the government, market cooperation and social synergy. On the one hand, the government continues to strengthen its intervention and guiding role to promote the healthy, orderly and steady progress of urban renewal. On the one hand, the relationship between the government and the market and society should be reconstructed to give full play to the vitality of the market, mobilize all available resources, and call on and guide social organizations and residents to make decisions through the public publicity of policies and systems, so as to improve the enthusiasm of participating in the renewal.

Secondly, in the operation system of urban renewal, we should practice human-centered urban renewal activities and coordinate the interests of various actors. There should be a healthy interaction between the government and the public. On the one hand, the government introduces relevant policies to let the public know its main role in urban renewal. Under the guidance of the government, social autonomous organizations are cultivated to provide advice and suggestions to collect reasonable and effective demands for urban renewal. On the other hand, the government cannot achieve the goal of urban renewal without the support and assistance of all sectors of society.

Finally, the guarantee system of urban renewal should be established to form a standardized urban renewal planning system. At the same time, the main responsible departments and cooperative departments of urban renewal should be defined, and the overall and supporting policies related to urban renewal should be jointly formulated and the overall planning should be compiled.

\section{CONCLUSION}

Urban renewal is an extremely complex activity, and many subjects play an indispensable role in urban renewal. The subjects are inseparable, interdependent and mutually restricted. Under the concept of actor network, the role of various actors in urban renewal should be properly handled, relations between various parties should be coordinated, interests should be balanced, and efficient interaction should be conducted in urban renewal to better realize urban construction and development.

\section{REFERENCES}

[1] Wang Shifu, Zhang Xiaoyang, Fei Yan.Urban and Rural Planning,2018(04):14-21+32.]

[2] Roberts Sykes.Urban Renewal Manual [M]. Beijing: China Architecture and Building Press, 2009:68.
[3] [Yang J Q. The present situation, characteristics and trend of urban renewal in China [J]. City Planning Review,2000,24 (4):53-55.]

[4] Liu Wenxuan, From the Construction of Knowledge to the Construction of Practical Affairs, Philosophical Research, No.5, 2017

[5] Bruno latour, science in action: how to follow scientists and engineers in society, Oriental press, 2005, p. 418.

[6] Chen Peipei, Zhang Min.The social spatial reconstruction of Dashiao village [J].Geographical Research, 2015(8) : 1435-1446

[7] Latour B.Reassembling.the social:an introduction to actor-network-theory.New York.Oxford University Press.2005.p.37.

[8] Lv Xiaobei, Zhao Ruoyan. Reflections on the Construction of Urban Renewal System in Shenzhen [J].Urban Planning, 2009, v.33;No.256(4):57-60. 